Provided for non-commercial research and education use. Not for reproduction, distribution or commercial use.

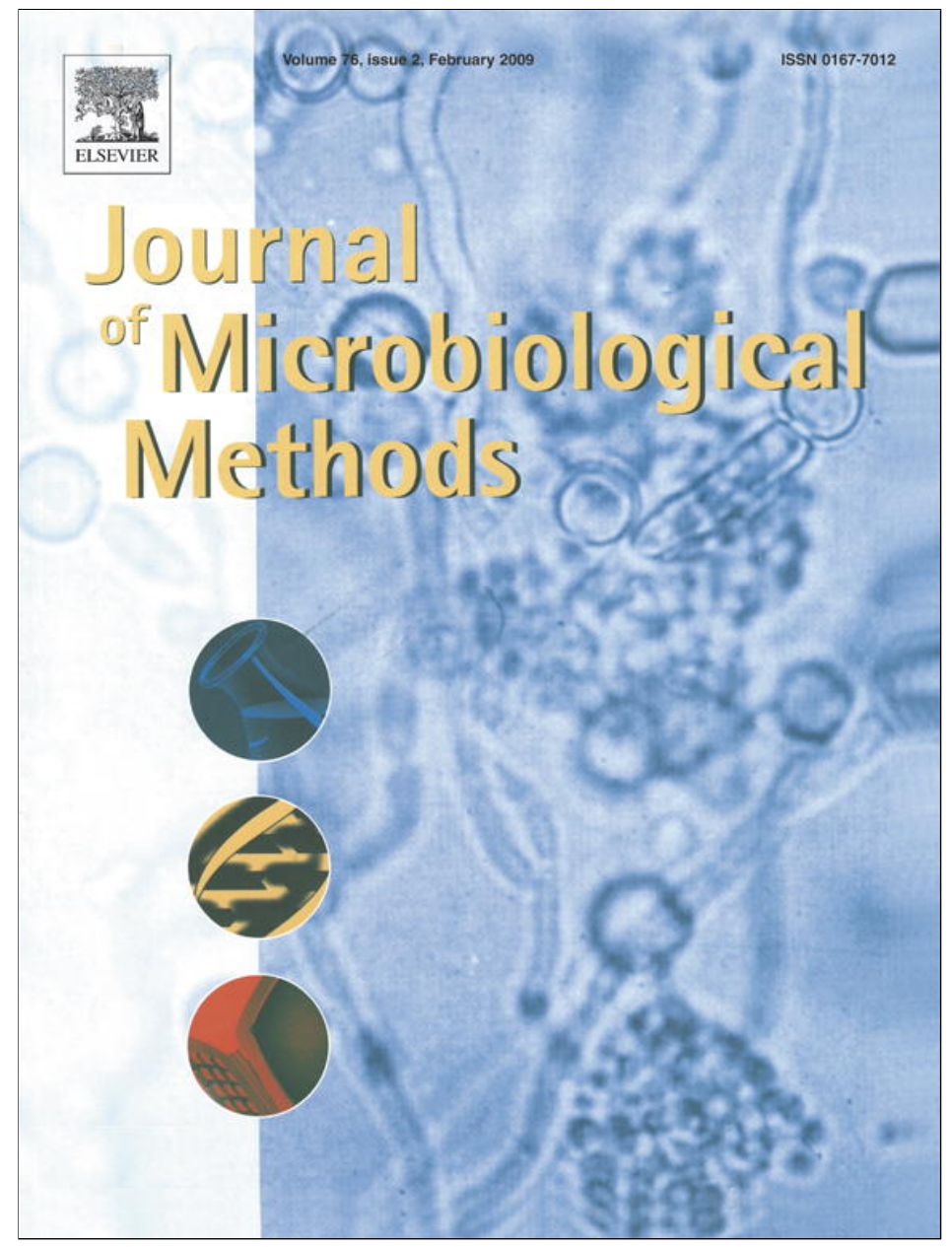

This article appeared in a journal published by Elsevier. The attached copy is furnished to the author for internal non-commercial research and education use, including for instruction at the authors institution and sharing with colleagues.

Other uses, including reproduction and distribution, or selling or licensing copies, or posting to personal, institutional or third party websites are prohibited.

In most cases authors are permitted to post their version of the article (e.g. in Word or Tex form) to their personal website or institutional repository. Authors requiring further information regarding Elsevier's archiving and manuscript policies are encouraged to visit:

http://www.elsevier.com/copyright 


\title{
Overcoming the anaerobic hurdle in phenotypic microarrays: Generation and visualization of growth curve data for Desulfovibrio vulgaris Hildenborough
}

\author{
Sharon Borglin *, Dominique Joyner, Janet Jacobsen, Aindrila Mukhopadhyay, Terry C. Hazen \\ Lawrence Berkeley National Laboratory, Berkeley, CA, USA \\ Virtual Institute for Microbial Stress and Survival, USA
}

\section{A R T I C L E I N F O}

\section{Article history:}

Received 8 September 2008

Received in revised form 4 October 2008

Accepted 4 October 2008

Available online 22 October 2008

\section{Keywords:}

Desulfovibrio vulgaris Hildenborough

Sulfate reducing bacteria

Phenotypic microarray

Omnilog

Anaerobes

Phenotype

$\mathrm{pH}$ stress

$\mathrm{NaCl}$ stress

\begin{abstract}
A B S T R A C T
Growing anaerobic microorganisms in phenotypic microarrays (PM) and 96-well microtiter plates is an emerging technology that allows high throughput survey of the growth and physiology and/or phenotype of cultivable microorganisms. For non-model bacteria, a method for phenotypic analysis is invaluable, not only to serve as a starting point for further evaluation, but also to provide a broad understanding of the physiology of an uncharacterized wild-type organism or the physiology/phenotype of a newly created mutant of that organism. Given recent advances in genetic characterization and targeted mutations to elucidate genetic networks and metabolic pathways, high-throughput methods for determining phenotypic differences are essential. Here we outline challenges presented in studying the physiology and phenotype of a sulfatereducing anaerobic delta proteobacterium, Desulfovibrio vulgaris Hildenborough. Modifications of the commercially available OmniLogTM system (Hayward, CA) for experimental setup, and configuration, as well as considerations in PM data analysis are presented. Also highlighted here is data viewing software that enables users to view and compare multiple PM data sets. The PM method promises to be a valuable strategy in our systems biology approach to $D$. vulgaris studies and is readily applicable to other anaerobic and aerobic bacteria.
\end{abstract}

Published by Elsevier B.V.

\section{Introduction}

Desulfovibrio vulgaris Hildenborough, a sulfate-reducing anaerobic, delta proteobacterium, has been identified as a model organism in many types of sulfate-reducing environments, especially those related to metal-contaminated sites (Caumette, 1993; Telang et al., 1994; Noguera et al., 1998; Cottrell and Cary, 1999; Wind et al., 1999; Heidelberg et al., 2004). Detailed studies on growth and metabolism of this organism are necessary to understand metal reduction processes under a variety of environmental conditions. Conducting a growth curve to determine lag time, growth rate, and maximum cell densities often is necessary to understand the physiology or phenotype and the specific effect of environmental stressors on the organism. Culturing in batch cultures has the disadvantage of large amounts of media with single or multiple component differences, of large numbers of tubes or flasks, and of the inconvenience of manually monitoring optical densities of large numbers of cultures. In addition, growth times often are difficult to predict and key experimental data may be lost if

\footnotetext{
* Corresponding author. Ecology Department, Earth Sciences Division, Lawrence Berkeley National Laboratory, 1 Cyclotron Road, MS 70-A-3317, Berkeley, CA 94720. Tel.: +1 510486 7515; fax: +1 5104867152 .

E-mail address: seborglin@lbl.gov (S. Borglin).

URL's: http://vimss.lbl.gov (S. Borglin), http://vimss.lbl.gov (D. Joyner), http://vimss.lbl.gov (J. Jacobsen), http://vimss.lbl.gov (A. Mukhopadhyay), http://vimss.lbl.gov (T.C. Hazen).
}

sampling is not sufficiently frequent (Sani et al., 2003). Increased convenience and quantity of the data can be obtained by automation of the growth curve measurements in 96-well microtiter plates (hereafter referred to as plates). After preparation, plates can be incubated and growth monitored by recording opacity changes by automation at discrete intervals, continuously over several days. The opacity response was recorded as a positive integer which we have named OmniLog ${ }^{\mathrm{TM}}$ units (OL units) which were calibrated to standard microbiological techniques. The high throughput 96-well plate format also facilitates replication so that growth from either technical or biological replicates can be compared simultaneously on a single plate.

Biolog (Hayward, CA) has developed a microarray for rapid characterization of an organism based on phenotypic response to substrate utilization. The instrument, called the OmniLog ${ }^{\mathrm{TM}}(\mathrm{OL})$, is designed to simultaneously measure phenotypic responses from a standardized inoculum to almost 2000 substrates, grouped into arrays. The Phenotype MicroArray (PM) panels, designed for use in the OL, consist of twenty pre-prepared 96-well plates that include substrates to test carbon, nitrogen, sulfate and phosphate utilization, as well as ionic, osmotic, $\mathrm{pH}$ and chemical sensitivity assays. In addition to the PM plate assays, the OL can also be used to visualize growth in standard empty plates with user-defined media components.

The focus of this study was the development of methods for surveying and visualizing the growth of the anaerobic sulfate reducing bacteria, $D$. vulgaris, using the Omnilog ${ }^{\mathrm{TM}}$ workflow. While an evaluation 
of the complete phenotype of $D$. vulgaris is beyond the scope of this study, phenotypic data recorded using these methods is included in the supplementary data.

\subsection{Previous work: Anaerobic growth on microtiter plates}

Microtiter plate readers can rapidly measure turbidity or color development in the wells of a plate, and most instruments can both incubate plates and log the data. Typical growth using plates is quantified by measuring absorbance of a tetrazolium dye at a specific wavelength or by pixel intensity measurement from a flat bed scanner or camera system (Bhupathiraju et al., 1999; Gabrielson et al., 2002; Bochner, 2003). Originally developed for aerobic microbes, with appropriate modifications 96 well plates can also be used in the characterization of sulfate reducers and other anaerobic bacteria. Microbes that are pathogenic or virulent to human, animal stock or agriculture are historically the most well studied anaerobic bacteria. These and clinical variants of these strains constitute a critical group of microbes that continue to be studied. Recent research emphasis on environmental anaerobic microbial systems has further broadened the interest in rapid phenotypic profiling of bacteria found in the environment. Examples include Clostridium spp. for biofuels research (Demain et al., 2005), Dehalobacter sp. and Dehalococcoides spp. for bioremediation (Grostern and Edwards, 2006), and sulfate- and metal-reducing bacteria such as Desulfovibrio spp. and Geobacter spp. for heavy metal biocontainment (Chang and Kim, 2007; Martinez et al., 2007; Neculita et al., 2007; Yi et al., 2007).

Previous researchers have adapted the plate method for studying facultative anaerobes. In a study on growth inhibition, Salmonella enteriditis, Escherichia coli, and Paracoccus denitrificans were grown on plates in a variety of media under anaerobic conditions (Brewster, 2003; Koutny and Zaoralkova, 2005), The lids were sealed onto plates with silicone and then flushed with nitrogen to remove oxygen. Problems with condensation during incubation were overcome with the use of anti-fogging agents on the lids. This study observed anaerobic growth by measuring turbidity on a microplate reader at $550 \mathrm{~nm}$ which was calibrated with direct cell counts. Other toxicity tests of facultative anaerobes in plates, also with the silicon sealant method, were used to observed growth of natural and engineered luminescent bacteria Vibrio fischeri and Pseudomana putida (Schmitz et al., 1999a; Gellert, 2000) for determination of $50 \%$ and $20 \%$ inhibitory concentrations. The authors of these studies concluded that to calculate toxicity as measured by the assay, both integral (area under the curve) calculation and endpoint calculation methods can demonstrate different toxicity levels. Schmitz et al. (1999a,b) also proposed using kinetic measurements rather than the maximum absorbance value obtained from the growth curve for calculation of growth inhibition because some compounds increased the absolute values, due to abiotic or background absorbance effects, but not the rate of growth. To determine Minimum Inhibitory Concentrations (MIC), dose-response relationships were developed by plotting growth retardation vs. $\log$ concentration using the intercept to compare retardation amounts. This method was shown to be effective in quantifying differences in growth (Schmitz et al., 1999b) and was useful for interpreting data in which the toxic compounds being tested affected turbidity thereby making lag time, maximum optical density (OD), and growth rate difficult to quantify. It was observed that for some tested compounds abiotic reactions in the medium may increase or decrease background, so care must be taken in comparing growth curves in different media compositions.

During D. vulgaris growth, sulfate is reduced to hydrogen sulfide, which reacts with metals, mainly $\mathrm{Fe}^{+2}$, in defined lactate sulfate medium, forming black metal/iron sulfide precipitates (Postgate and Campbell, 1966). The increased opacity, caused by increase in cell numbers and precipitation of metal sulfides, can be used in most growth conditions as an analog for growth. Use of tetrazolium dyes have been successful with some anaerobic systems (Bhupathiraju et al. 1999); however, abiotic reduction of the tetrazolium salt occurs in the lactate sulfate medium when the reducing agent (titanium citrate) is added to reduce the medium, making the use of these dyes ineffective.

In this paper, techniques are described for observing anaerobic growth of the sulfate-reducing bacterium, D. vulgaris, in PM plates using increased opacity as a growth indicator. Growth was monitored by automatically recording opacity changes at 15 minute intervals over several days. The opacity response was recorded as a positive integer, named OmniLog ${ }^{\mathrm{TM}}$ units (OL units) which were calibrated to standard microbiological techniques. The development of PM technology for the characterization of this anaerobic sulfate-reducing bacterium was made possible through chemical, engineering, and mechanical modifications to the standard PM protocol (Biolog, Hayward, CA) and represents a novel and important new tool for screening of anaerobic bacterial phenotypes. Described here are methods for preparation of cells for general growth curve measurement, as well as stress and media component testing along with precautions taken during interpretation of PM results. Key to analysis and interpretation of data is processing and visualization. Included in this paper is the description of a Web-based software package for visualizing growth curves. These software tools allow for more complete understanding of PM data and ease viewing and sharing of large data sets with collaborators.

\section{Materials and methods}

A schematic of the sample preparation techniques is shown in Fig. 1. D. vulgaris was grown from a $-80^{\circ} \mathrm{C}$ preserved stock culture (ATCC 29579 , Manassas, VA) in a defined lactate-sulfate medium(LS4D). LS4D medium contains $50 \mathrm{mM} \mathrm{NaSO}_{4}, 60 \mathrm{mM}$ sodium lactate, $8 \mathrm{mM} \mathrm{MgCl}, 20 \mathrm{mM}$ $\mathrm{NH}_{4} \mathrm{Cl}, 2.2 \mathrm{mM} \mathrm{KPO}_{4}, 0.6 \mathrm{mM} \mathrm{CaCl}_{2}, 30 \mathrm{mM}$ PIPES buffer, 0.016 Resazurin, $10 \mathrm{mM} \mathrm{NaOH}, 1 \mathrm{~mL} / \mathrm{L}$ Thauers vitamins, $12.5 \mathrm{~mL} / \mathrm{L}$ trace minerals, and $5 \mathrm{~mL} / \mathrm{L}$ titanium citrate. The trace minerals stock contains $50 \mathrm{mM}$ nitrilotriacetic acid, $5 \mathrm{mM} \mathrm{FeCl} 2 * 4 \mathrm{H}_{2} 0,2.5 \mathrm{mM} \mathrm{MnCl} 2 * 4 \mathrm{H}_{2} \mathrm{O}, 1.3 \mathrm{mM}$ $\mathrm{CoCl}_{2} * 6 \mathrm{H}_{2} \mathrm{O}, 1.5 \mathrm{mM} \mathrm{ZnCl}, 210 \mu \mathrm{M} \mathrm{Na}_{2} \mathrm{MoO}_{4} * 4 \mathrm{H}_{2} \mathrm{O}, 320 \mu \mathrm{M} \mathrm{H}_{3} \mathrm{BO}_{3}$, $380 \mu \mathrm{M} \mathrm{NiSO}_{4} * 6 \mathrm{H}_{2} \mathrm{O}, 10 \mu \mathrm{M} \mathrm{CuCl}_{2} * 2 \mathrm{H}_{2} \mathrm{O}, 30 \mu \mathrm{M} \mathrm{Na}_{2} \mathrm{SeO}_{3}$, and $20 \mu \mathrm{M}$ $\mathrm{Na}_{2} \mathrm{WO}_{4} * 2 \mathrm{H}_{2} \mathrm{O}$. The Thauers vitamins stock contains $82 \mu \mathrm{M}$ d-biotin, $45 \mu \mathrm{M}$ folic acid, $490 \mu \mathrm{M}$ pyridoxine hydrochloride, $150 \mu \mathrm{M}$ thiamine hydrochloride, riboflavin, $410 \mu \mathrm{M}$ nicotinic acid, $210 \mu \mathrm{M}$ pantothenic acid, $310 \mu \mathrm{M}$ p-aminobenzoic acid, $240 \mu \mathrm{M}$ thioctic acid (lipoic acid), $14 \mu \mathrm{M}$ choline chloride, and $7.4 \mu \mathrm{M}$ vitamin B12 (Mukhopadhyay et al., 2006).

D. vulgaris was grown at $30^{\circ} \mathrm{C}$ in an anaerobic atmosphere consisting of $5 \% \mathrm{CO}_{2}, 5 \% \mathrm{H}_{2}$, balance $\mathrm{N}_{2}$ (Airgas, Concord, $\mathrm{CA}$ ) to mid-log phase. Cell inoculum was standardized to ensure repeatable conditions between experiments. Mid-log phase cells, with density of $1 \times 10^{8}$ cells $/ \mathrm{mL}$, were pelleted at $6000 \mathrm{~g}$ for $15 \mathrm{~min}$. After removal of the supernatant, the pellet was resuspended and homogenized by pipetting into plate-specific medium (see Table 1 and description below) to achieve a final concentration of $1 \times 10^{7}$ cells $/ \mathrm{mL}$, corresponding to approximately 10 OL units. The resuspended cells were then pipetted onto the 96-well plates at a volume of $100 \mu \mathrm{L} /$ well. Plates used with both OL PM arrays and user-prepared media are standard, clear, half area plates with flat bottoms and are designed to hold $100 \mu \mathrm{L}$ volume per well.

Engineering modifications were made for the anaerobic incubation of the inoculated plates. When the sealant method was attempted, poor on no growth was observed in the wells closest to the edge of the plate indicating oxygen leakage or potentially toxic effects from the sealant. Instead, prior to removal from the anaerobic chamber, inoculated plates were placed into 4 oz Whirl-Pak ${ }^{\circledR}$ Long-Term Sample Retention Bags (Nasco, Fort Atkinson, Wisconsin) and the open end was sealed $2 \mathrm{~mm}$ wide heat sealer (American International Electric, Newport News, Virginia). The Nasco bags are $2.5 \mu \mathrm{m}$ thick and have a reported oxygen permeability of $0.125 \mathrm{~mL} / 645 \mathrm{~cm}^{2} / 24 \mathrm{~h}$ and a water vapor transmission rate of $0.48 \mathrm{gms} / 645 \mathrm{~cm}^{2} / 24 \mathrm{~h}$ at $22.8{ }^{\circ} \mathrm{C}$ (information provided by manufacturer). After sealing, the bag surface area is $284 \mathrm{~cm}^{2}$ (including the top and bottom surfaces) and volume is $180 \mathrm{~cm}^{3}$. With an incubation time of $60 \mathrm{~h}$ and this bag geometry, at $22.8^{\circ} \mathrm{C}$ the calculated water loss would be $0.528 \mathrm{~g}$ and the oxygen 


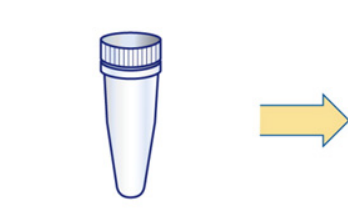

$-80^{\circ} \mathrm{C}$ DvH Stock

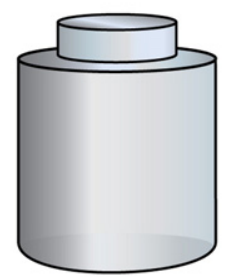

$1 \%$ Inoculum in Regular LS4D, Grow to $10^{8}$ Cells/ml

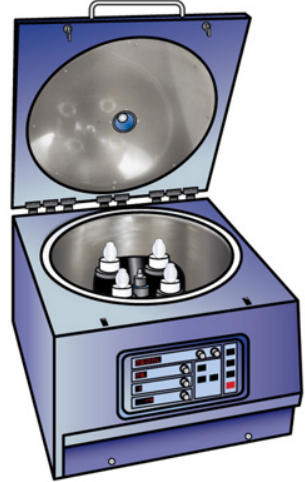

Centrifuge $15 \mathrm{~min}, 6000 \mathrm{~g}$, to Remove Old Media
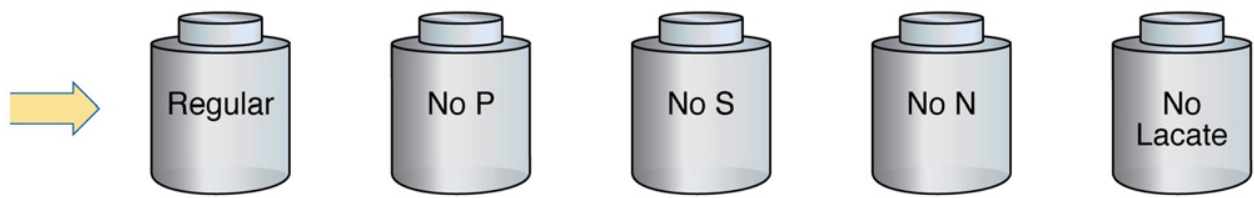

Resuspend Cells in Omnilog Media (see Table 1). Final Cell Concentration $10^{7} \mathrm{Cells} / \mathrm{ml}$

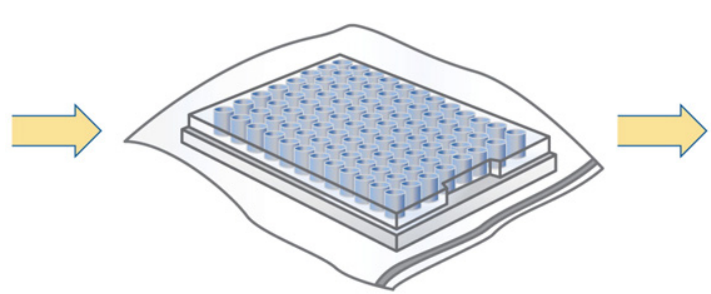

Inoculate Plates in an Anerobic Chamber, 100 ul per Well, and Seal in Plastic Bags
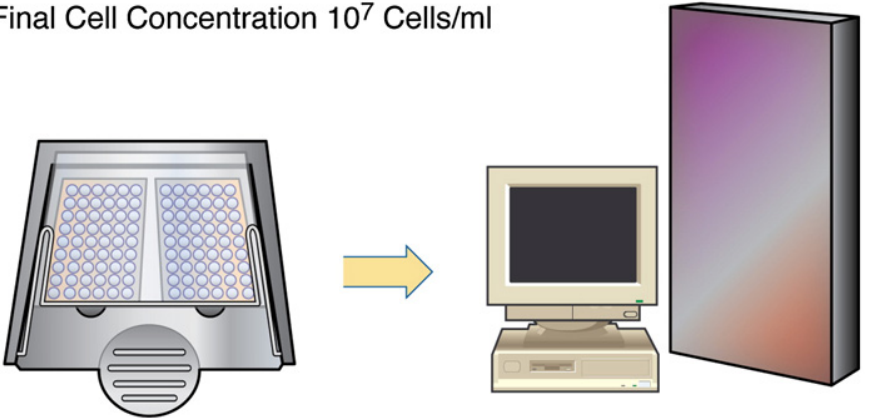

Plates are Clamped into Trays and Incubated in the Omnilog

ESD08-003

Fig. 1. Schematic of the preparation steps for the PM microplates for D. vulgaris.

entering the bag would be $0.1375 \mathrm{~mL}$, or $5.5 \%$ of the initial volume lost and a final oxygen concentration of $0.076 \%$. While this is relatively minor, losses at higher temperatures or longer incubations times may be significant and should be taken into consideration. To verify water loss in our system, plates were prepared with $100 \mu \mathrm{L}$ of media per well and incubated for $48 \mathrm{~h}$ at $30^{\circ} \mathrm{C}$ which resulted in measured water loss of $0.018 \mathrm{~g} / 645 \mathrm{~cm}^{2} / 24 \mathrm{~h}$. Our lower observed value is most likely due to the geometry of the plate, the low volume of water overall, and because the plates, except when reading, are housed between two metal plates which may reduce water vapor transmission. Oxygen was monitored both by indicator strips and by the presence of resazurin in the media. It was established that with this method anaerobic conditions lasted for at least $80 \mathrm{~h}$ in the $\mathrm{OL}$ at $30^{\circ} \mathrm{C}$ without problems of fogging or toxicity from silicon or other sealants.

While these bags were effective in maintaining anaerobic conditions, it was found that the plastic bags frequently jammed in the instrument due to the physical size and mechanical motion of the plate reader. Metal clamps were added to properly seat the bagged microtiter plate into the tray to reduce friction from the bag and the possibility of jamming during plate reading, as well as to hold the plates horizontally in the trays so that the detector could gather nondistorted images.

To start incubating, bagged and sealed plates were removed from the anaerobic chamber, clamped in trays and incubated at $30{ }^{\circ} \mathrm{C}$ in the OL until a maximum OL value was reached. The plate was automatically scanned by the instrument and opacity (by pixilation intensity) was recorded every $15 \mathrm{~min}$. Cell growth was observed in both user prepared 96-well plates and Biolog-prepared PM plates PM 1-PM 20 (Biolog, Hayward, CA). A full listing of all PM array well substrates can be found on the Biolog website (http://www.biolog. $\mathrm{com} / \mathrm{pmMicrobialCells.html)}$ and in the supplementary materials.

The scanning technology used by the OL records the increased in well opacity as digital OL units. These OL units were given a microbiological value by calibrating to OD at $600 \mathrm{~nm}$ and cell count data (see Results

Table 1

LS4D media preparation guidelines

\begin{tabular}{|c|c|c|c|c|c|c|}
\hline LS4D type & PM plates & $\begin{array}{l}\text { LS4D } \\
(\mathrm{mL})\end{array}$ & $\begin{array}{l}\text { Culture } \\
(\mathrm{mL})\end{array}$ & $\begin{array}{l}\text { Vitamins } \\
(\mu \mathrm{L})\end{array}$ & $\mu \mathrm{LTC}^{\mathrm{a}}$ & Atm \\
\hline No lactate & 1,2 & 30 & 3 & 30 & 150 & \\
\hline No $P$ & 4 (rows A-E) & 10 & 1 & 10 & 50 & \\
\hline No $S$ & 4 (rows F-G) & 10 & 1 & 10 & 50 & $\begin{array}{l}5 \% \mathrm{CO}_{2}, 5 \% \\
\mathrm{H}_{2} \text {, balance }\end{array}$ \\
\hline No vitamins & 5 & 10 & 1 & 0 & 50 & $\mathrm{~N}_{2}$ \\
\hline Standard & $9-20$ & 150 & 15 & 150 & 750 & \\
\hline No $\mathrm{N}$ & $3,6,7,8$ & 60 & 6 & 60 & 300 & Argon \\
\hline
\end{tabular}

a TC: Titanium citrate reducing agent. 
section below). The cell count calibration was achieved by sacrificing plates and sampling cells from the 96-well plates at various stages of growth representing a range of OL units and quantified using acridine orange (Sigma-Aldrich, St. Louis, MO) direct cell counts (AODC) (Francisco et al., 1973) and measured at $\mathrm{OD}_{600}$ using a standard spectrophotometer (Perkin Elmer, Waltham, Massachusetts).

To accommodate the various plate-specific phenotype testing, LS4D medium was modified for each type of PM plate (Table 1). In PM 1 and 2, carbon substrate utilization is evaluated; therefore, medium was made without addition of the LS4D carbon source lactate. Nitrogen was removed by omitting the medium component $\mathrm{NH}_{4} \mathrm{Cl}$ for PM 3 (N sources), 6, 7, and 8 (peptide $\mathrm{N}$ sources) plates, which assay a variety of nitrogen substrates and amino acids. In addition, because $D$. vulgaris contains nif genes on its native plasmid that support growth on N2 (Heidelberg et al., 2004) PM 3, 6, 7, and 8 plates were prepared in an Ar atmosphere. For PM 4, which assays P and S utilization pathways, $P$ was removed from LS4D for rows A-E, and S was removed for rows F-G. Plates PM 9 and 10 evaluate the effects of osmotic and pH stress, and plates PM 11-20 contain a wide variety of inhibitors. For PM 9-20 standard LS4D medium was used. For the PM 1-8 plates, which use media without a critical nutrient or substrate, the plates contain control wells to monitor growth in the inoculated media without the added component. Growth in control wells indicate faulty or over-inoculation, so that the data from the entire plate could be rejected.

\section{PMViewer software}

Because of the potentially large number of growth curves produced in a phenotype microarray experiment and the need to easily share (a)

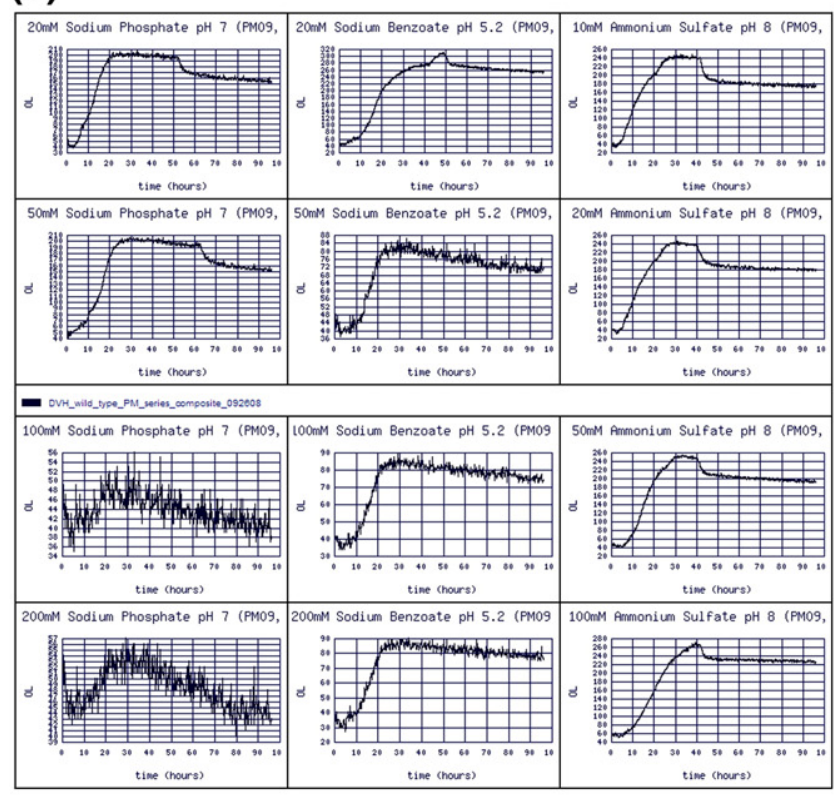

(c)
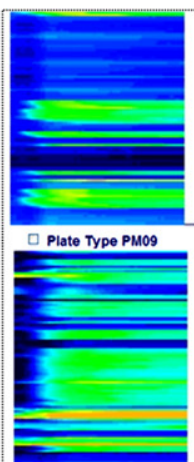

口 Plate Type PM13A

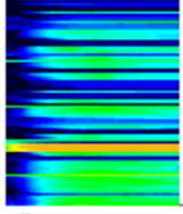

Plate Type PM17A
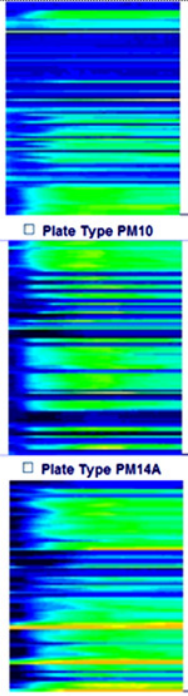

口 Plate Type PM18A
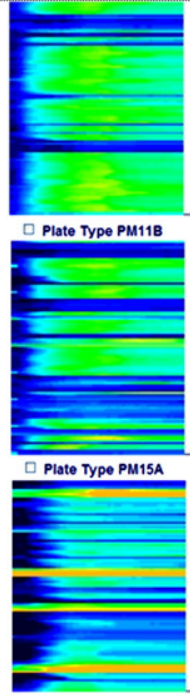

口 Plate Type PM19 (b)

50mM Ammonium Sulfate $\mathrm{pH} 8$ (PM09, G11)

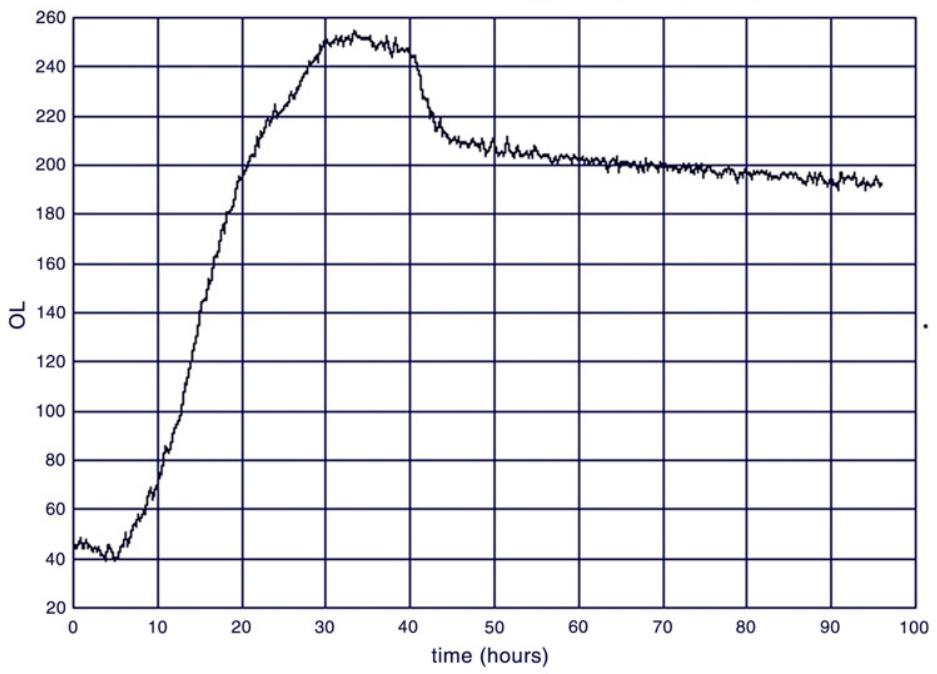

(d)

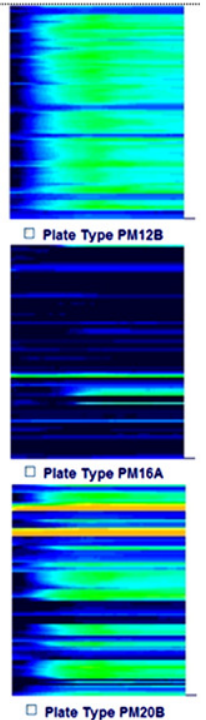

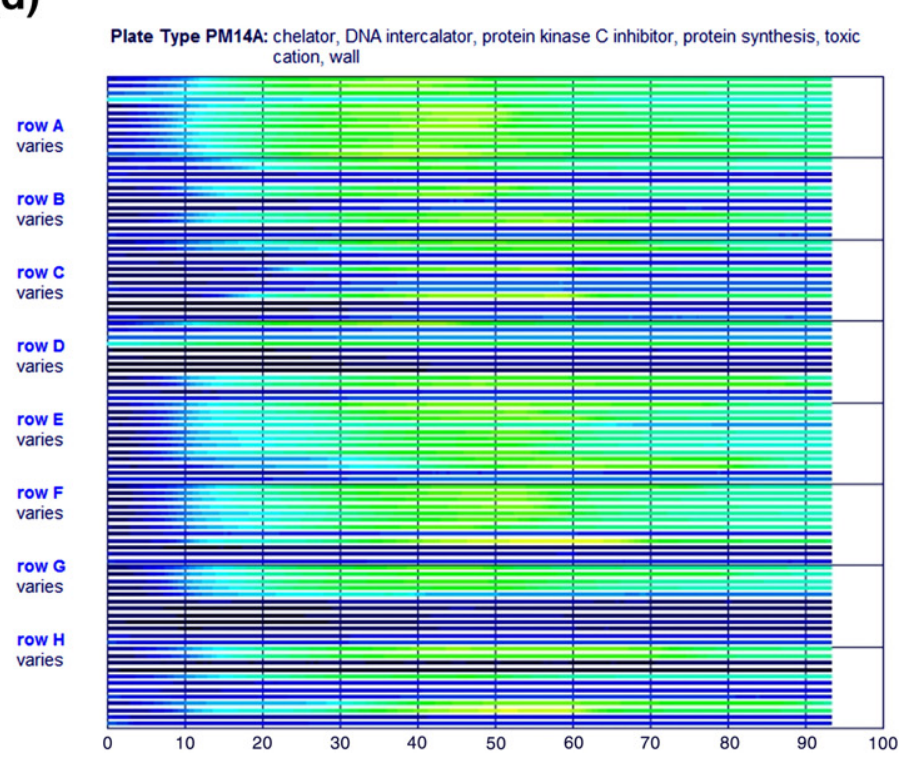

Fig. 2. Screenshot of PMRowView Web-based data viewer is shown in (a). This view shows twelve plots corresponding to the twelve wells on a single row of a PM microplate. Selecting a plot will open a new window that displays the plot on a larger scale (full page) and that has a link to download the data as a CSV file as shown in (b). Plot (c) groups all available PM microplates for a single run in a preview mode in the PMColorView Web data viewer. Each plot, when selected will produce the plot for a single plate as shown in (d). Selecting a color band (i.e., a microwell) in (d) will produce a full-size plot (b) for the selected microwell, as well as a link to download the raw data. 
results, we have developed a number of Web-based interfaces to display growth curve data. Biolog ${ }^{\mathrm{TM}}$ provides software for data viewing with the OL instrument, but it is not Web based and requires installation on individual computers for viewing PM data and the transfer of data files between computers. The PMViewer software that we developed has a database backend and provides different views of the data using Web-based interfaces.

The main data viewer for the results is PMRowView. This interface allows the user to select one or more PM datasets, a single plate type, and a row on that plate. For the purpose of the data viewers, a PM dataset consists of growth curve data from a phenotype microarray experiment involving a single strain of an organism and a set of distinct PM plates run on the same day. Growth curves are plotted twelve to a (Web) page in a threecolumn, four-row format (Fig. 2a). Each plot is labeled with the chemical name, plate type, and well id. Because some chemicals are used to treat four consecutive wells (using different doses) on a plate, the plots are placed on the page so that when a chemical is repeated, growth curves for all four doses appear in one column to facilitate comparing dose responses. If the user clicks on one of the twelve small plots, a new window will open that shows a larger version of that plot (example shown in Fig. 2b). In the new window, the user has the option to download the data as a tab-delimited file for the curve(s) shown in the plot.

One additional feature of the PMRowView is that if the user selects a single dataset to view, then in addition to the plot of the growth curve, approximate accumulation times are displayed. The accumulation time is approximated as follows. A four-point centered averaging method is applied first in order to smooth the curve. The time at which the maximum value, $v_{\max }$, of the curve is attained is determined, and following that, the times at which points on the curve equal $10 \%, 20 \%$, $30 \%, \ldots 90 \%$ of the maximum value are determined. Four approximate accumulation times, AT, are calculated from $\mathrm{AT}\left(t_{\mathrm{a}}, t_{\mathrm{b}}\right)=t_{\mathrm{b}}-t_{\mathrm{a}} / 3.3 \log _{10}$ $\left(v_{\mathrm{b}} / v_{\mathrm{a}}\right)$ using the times and values corresponding to the $10 \%$ and $90 \%$ points, $20 \%$ and $80 \%$ points, $30 \%$ and $70 \%$ points, and $40 \%$ and $60 \%$ points. For example, for the $10 \%$ and $90 \%$ points, $v_{\mathrm{b}}\left(t_{\mathrm{b}}\right)=0.9 v_{\max }$ and $v_{\mathrm{a}}$ $\left(t_{\mathrm{a}}\right)=0.1 v_{\text {max }}$. In cases where there is no response, or the curve does not have a leading rising edge (i.e., the maximum value occurs earlier than the minimum value), the accumulation time is not approximated.

In this workflow, the OL unit is a measure of increased opacity due to cell growth processes, principally FeS precipitation, therefore the accumulation time determined above, though affected by growth rate, does not directly measure growth rate.

The PMRowView interface is useful for directly comparing the response of different strains of organisms for a given plate type. As many PM arrays are done in replicates, an extension of the PMRowView interface (not shown) plots averaged growth curve data, and markers showing plus or minus one standard deviation from the average value, from replicate runs of phenotype microarray experiments using the same organism and plate. This extension of the PMRowView interface is valuable both for assessing the reproducibility of replicate runs and for comparing the responses of different strains when there are replicate runs.

A second interface, the PMColorMap, was developed to facilitate the display of growth curve data for many plates or many experiments on a single Web page. The PMColorMap interface displays a growth curve as a thin horizontal line in which magnitude is represented by color (Fig. 2c). Using this technique, and by vertically stacking the horizontal lines representing the growth curves, it is possible to display all 96 curves for a single PM plate in a relatively small area. In the 'preview' mode of this interface, it is possible to display either color images representing all of the plates in a single dataset, or color images for a single plate type for multiple datasets. The first option shows at a glance plates for which there is poor growth overall, anomalies resulting from equipment malfunctions, or chemical reactions between the growth medium and the chemical treatment in the well (Figs. 3 and 8). The second option allows the user to make gross comparisons of the responses of different strains of an organism to the treatments on a single plate.

If the user clicks on a color image in the preview mode, a new window will open showing a larger version of the color image, in which the color lines representing each growth curve are distinct (Fig. 2d). Slowly moving the computer mouse over a color line displays the plate type, well id, chemical name, and mode of action. Clicking on a color line will open a new window showing the growth curve corresponding to the color line, i.e., corresponding to a single well (Fig. 2b). Clicking on the row label will open a new window in which the growth curves for the twelve wells in that row will be plotted as previously described for the PMRowView interface. The PMColorMap interface provides a quick look at both the responses of different strains of an organism and the quality of data for a phenotype microarray experiment. Examples of how the PMColorMap interface is used to check data quality are described in the following section.

The PMRowView and PMColorMap interfaces are Perl-CGI scripts that use the Perl module GD, available from the Comprehensive Perl Archive Network (CPAN, www.cpan.org), for creating the growth curve plots and the color images. Plots of growth curves (growth $v$. time) are generated on the fly, but the color map images, which are more computationally intensive to produce, are generated once and stored on the Web server. The approximate accumulation times also are calculated and stored on the Web server. The PMRowView and PMColorMap interfaces provide convenient and flexible ways of viewing phenotype microarray data (Jacobsen et al., 2007).

\section{Results and discussion}

\subsection{Inoculum standardization and calibration of OL value}

The PM plate analyses function by the addition of a key substrate to a deficient medium, or by adding an inhibitory chemical to limit growth. The goal is to inoculate wells uniformly to be able to visualize differential growth. Successful growth of $D$. vulgaris in plates was found to be a straightforward technique, however reproducible and representative growth in the PM array presented a methods development challenge. Several steps outlined in the methods section have detailed important modifications that are necessary for successful growth and testing of the $D$. vulgaris phenotype. As with any cell culture process, development of precise and consistent culture and inoculation techniques are very important to the production of high quality PM data from the OL system. Recognizing when representative

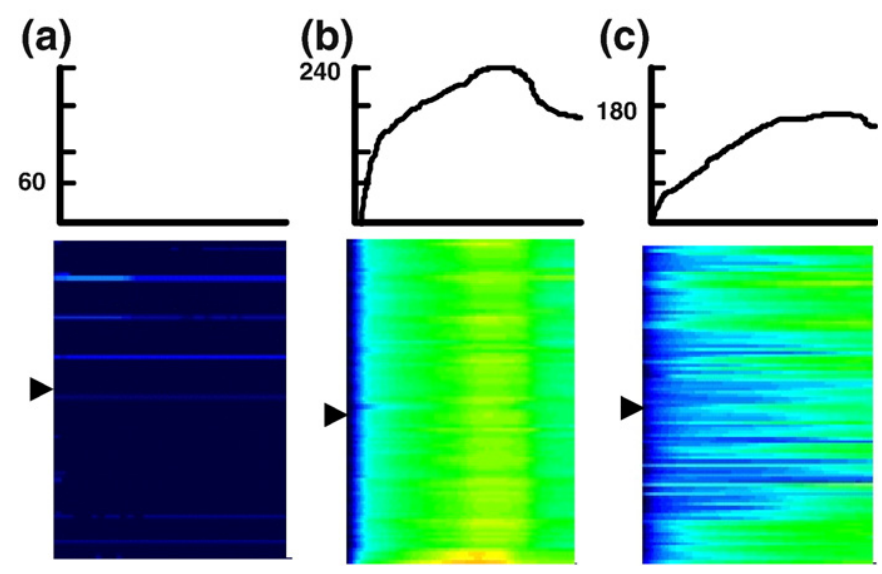

Fig. 3. False color images (see text) representing growth curves from 96-well microplates: (a) under inoculated microplate, (b) over inoculated microplate, (c) properly inoculated microplate. Arrows show location of wells whose growth curves are plotted above each color image. The color legend for these plots is shown in Fig. 2. 
growth has been visualized by the OL will prevent misinterpretation of results and will facilitate the generation of an accurate phenotype for an organism.

Fig. 3 demonstrates the three basic growth patterns that can be found after adding a new or unknown strain in a PM plate. Underinoculation results in no growth in all of the wells as shown in Fig. 3a. Alternatively, over-inoculation of the plate or failure to remove residual medium and dead cells from the inoculum (through centrifugation) often resulted in either cryptic or unmodified growth of D. vulgaris in the plates as shown in Fig. 3b. This growth is independent of the well contents and does not represent a valid phenotype. It was found that for D. vulgaris, if as little as $10 \%$ residual LS4D medium was transferred with the inoculum cells to the plates, growth on this carryover medium often superseded the limited growth in the PM well. Fig. $3 c$ demonstrates differential growth due to proper inoculation and removal of carryover medium and represents a valid assessment of phenotype. To assure that the observed plate results were valid, all results were confirmed in triplicate with biological replicates.

When different strains or mutants of a strain are compared, differences in growth rates or yields will have to be taken into account. To compare strains, their growth must be standardized or normalized to the parent strain, and if yields are sufficiently different between strains to make direct comparison difficult, it may be necessary to report differences as a percent change of normal growth in each strain rather than the absolute OL values.

Fig. 4a shows the results of standardized growth for D. vulgaris inoculated into empty, (MT), plates, showing an average of three biological replicates. Error bars represent measured standard deviations between the replicates, each run as 96 technical replicates. This growth of $D$. vulgaris, as described above in the methods section, represents an initial concentration of $1 \times 10^{-7}$ cells $/ \mathrm{mL}$ of mid-log phase cells in LS4D medium. In practice, this standardization of the inoculum concentration proved to be pivotal in producing representative growth, because adding lower concentrations of cells resulted in limited or no growth, and higher concentration showed abnormal growth curves. Fig. $4 \mathrm{~b}$ compares the observed OL data to a biological replicate measured in a Hungate tube at $600 \mathrm{~nm}$ and to a literature reported growth curve, also measured at $600 \mathrm{~nm}$ (Mukhopadhyay et al., 2006) demonstrating that the OL measurement of opacity and measured FeS accumulation rates are equivalent to $\mathrm{OD}_{600}$ measurements in standard LS4D (see Table 2).

(a)

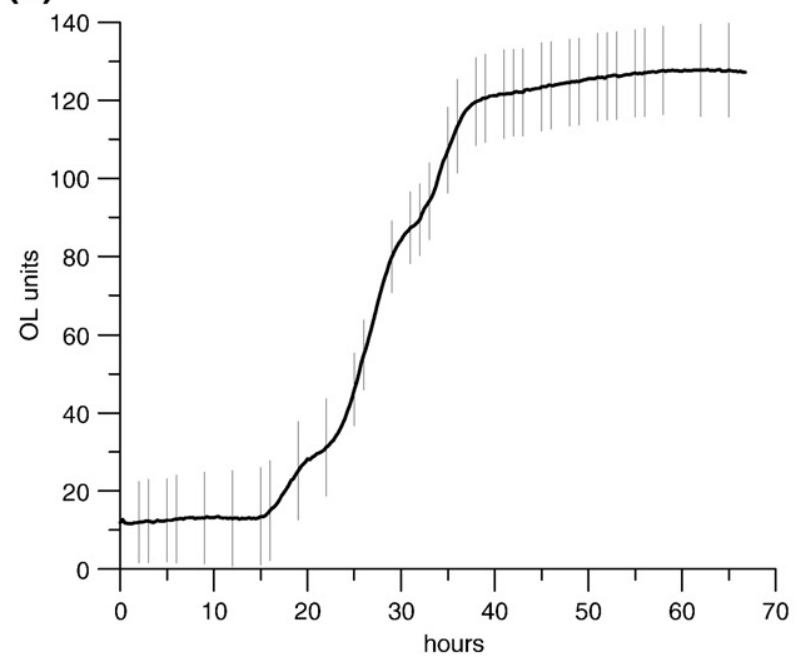

The observed increase in opacity was calibrated to standard cell enumeration techniques: cell counts and spectrophotometric measurement of turbidity at $600 \mathrm{~nm}\left(\mathrm{OD}_{600}\right)$ (see Fig. 5). Calibration was accomplished by preparing a wide range of cells concentrations and measuring by all three techniques. The calibration demonstrated the following relationships between OL units and cell density:

Log cell density $=1.89 * \ln ($ OL units $)+10.5$

$\left(r^{2}=0.9329\right)$, or on the order of $1 \times 10^{8}$ cells $/ \mathrm{mL}$ for an observed value of 120 OL units (see Fig. 5), and for OD $600 \mathrm{~nm}$ :

OD $600 \mathrm{~nm}=8.4 \times 10^{-3}($ OL units $)+0.03$

\section{$\left(r^{2}=0.9332\right)$.}

These calibrations of opacity measurement was necessary in order to further validate that increase in opacity with time measured by the OL using the darkening color, both from FeS precipitate and other cell products, indeed serves as an analog for increase in cell density over time. Similar to $\mathrm{OD}_{600}$ measurements, $\mathrm{OL}$ data does not measure exponential growth, but rather reflects the increased opacity due to accumulation of cells (as a function of the increase in number of cells) and metal sulfide precipitation within a defined range, which for OL units is 0 to 250 . As can be seen by the relationship between cell counts and OL units, the relationship is non-linear and lacks sensitivity at both the low and high cell counts. While cell counting remains as one of the most robust methods for monitoring growth, it is not possible to assay cell density in nearly 2000 substrates every 15 min. In contrast, the PM represents a high throughput tool to determine overall phenotype. Therefore, if an interesting phenotype is detected, additional validation by cell count assays must be obtained when using MT plates and batch reactors.

\subsection{Artifacts associated with growth of D. vulgaris in microtiter plates}

During long incubation times OL units will eventually reach a plateau value when the FeS accumulation has reached a maximum value, both due to depletion of Fe in the media and cells reaching stationary phase. Due to changes in FeS precipitate, or cell clumping, cell lysis, or changes in chemistry in the wells, the plateau level may steadily decrease, increase, or show fluctuation. In addition some wells show biphasic or hump in growth curve as compared to batch experiments. This may be due to the complex nature of the FeS (b)

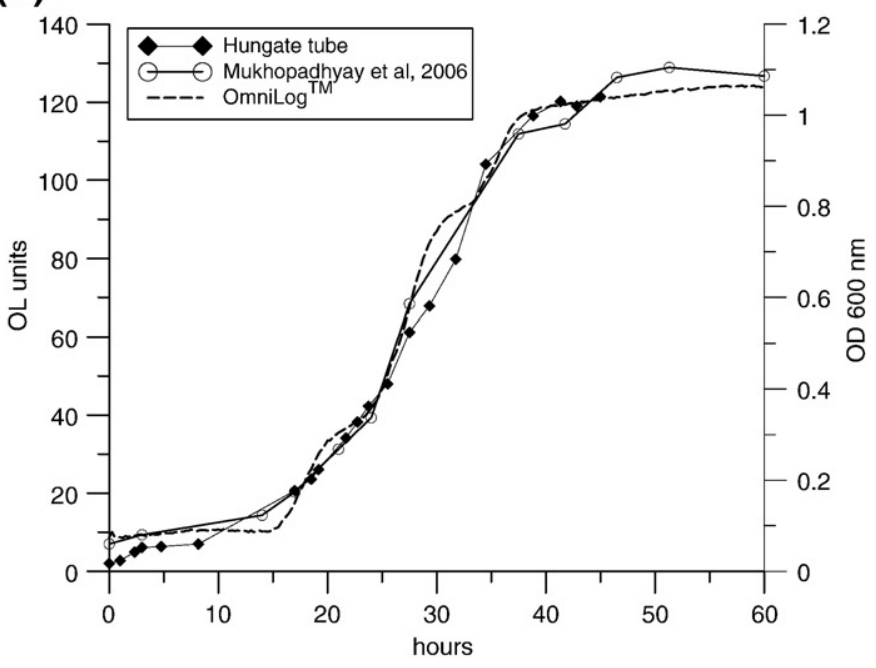

Fig. 4. (a) Representative growth curves from standardized inoculum. Shown are averages of three biological replicates of $D$. vulgaris growth in OL at $30^{\circ} \mathrm{C}$ in empty 96 well microtiter plates. Vertical lines represent one standard deviation. (b) Biological replicates of D. vulgaris growth in LS4D at $30{ }^{\circ} \mathrm{C}$ assays on the OmniLogTM, in hungate tubes and measured at $600 \mathrm{~nm}$, and literature reported growth curve (Mukhopadhyay et al., 2006). 
Table 2

Calculated accumulation rates (AR) of FeS precipitates from observed growth curves (see Fig. 4)

\begin{tabular}{|c|c|c|c|c|}
\hline$t_{\mathrm{a}}(\mathrm{h})$ & $t_{\mathrm{b}}(\mathrm{h})$ & $v_{\mathrm{a}}$ (OL units) & $v_{\mathrm{b}}$ (OL units) & $\mathrm{AR}=\left(t_{\mathrm{b}}-t_{\mathrm{a}}\right) /\left(3.3 * \log \left(v_{\mathrm{b}} / v_{\mathrm{a}}\right)\right)$ \\
\hline \multicolumn{5}{|c|}{$\overline{\text { OmniLogTM }}$} \\
\hline 17 & 37.5 & 17.52 & 116.48 & 7.551 \\
\hline 21 & 37.5 & 35.46 & 116.48 & 9.680 \\
\hline 24 & 37.5 & 41.74 & 116.48 & 9.179 \\
\hline 17 & 27.5 & 17.52 & 67.48 & 5.433 \\
\hline 21 & 27.5 & 35.46 & 67.48 & 7.049 \\
\hline 24 & 27.5 & 41.74 & 67.48 & 5.083 \\
\hline Average & & & & $7.3 \pm 1.9$ \\
\hline$t_{\mathrm{a}}(\mathrm{h})$ & $t_{\mathrm{b}}(\mathrm{h})$ & $v_{\mathrm{a}}(\mathrm{OD} 600 \mathrm{~nm})$ & $v_{\mathrm{b}}(\mathrm{OD} 600 \mathrm{~nm})$ & $\mathrm{AR}=\left(t_{\mathrm{b}}-t_{\mathrm{a}}\right) /\left(3.3 * \log \left(v_{\mathrm{b}} / v_{\mathrm{a}}\right)\right)$ \\
\hline \multicolumn{5}{|c|}{ Hungate tubes } \\
\hline 17 & 37.5 & 0.177 & 0.892 & 7.550 \\
\hline 21 & 37.5 & 0.292 & 0.892 & 8.033 \\
\hline 24 & 37.5 & 0.362 & 0.892 & 8.317 \\
\hline 17 & 27.5 & 0.177 & 0.524 & 6.750 \\
\hline 21 & 27.5 & 0.292 & 0.524 & 6.984 \\
\hline 24 & 27.5 & 0.362 & 0.524 & 7.075 \\
\hline Average & & & & $7.5 \pm 0.6$ \\
\hline \multicolumn{5}{|c|}{ Mukhopadhyay, 2006} \\
\hline 17 & 37.5 & 0.174 & 0.959 & 8.380 \\
\hline 21 & 37.5 & 0.268 & 0.959 & 9.030 \\
\hline 24 & 37.5 & 0.337 & 0.959 & 9.007 \\
\hline 17 & 27.5 & 0.174 & 0.586 & 6.034 \\
\hline 21 & 27.5 & 0.268 & 0.586 & 5.797 \\
\hline 24 & 27.5 & 0.337 & 0.586 & 4.414 \\
\hline Average & & & & $7.1 \pm 1.9$ \\
\hline
\end{tabular}

precipitation reaction and the combined effect of many co-occurring chemical or biological processes, or perhaps phage lysis that may affect well opacity. The differences observed in the plates as compared to standard batch experiments can be attributed to difference in culture geometry including size and shaking (mixing) of culture. Batch cultures are closed systems, whereas PM plates sealed in a bag are open systems and release of $\mathrm{H}_{2} \mathrm{~S}$ from other wells on the plate may change the chemistry of the medium during growth as compared to a closed batch. These are general features associated with growth in the OL, which have to be accounted for when interpreting results and comparing PM plates to other growth measurement techniques.

Because of the wide range of growth parameters that can be tested there is a possibility of mixotrophic growth occurring, where cells
Table 3

PM wells with unworkable abiotic reactions with D. vulgaris and LS4D media

\begin{tabular}{lll}
\hline PM microplate & Well position & Well contents \\
\hline 1 & C4, H6 & $\begin{array}{l}\text { D-Ribose, L-lyxose } \\
\text { 2-Hydroxybenzoic acid, sorbic acid, } \\
\text { dihydroxyacetone, 2-oxovaleric acid } \\
\text { E6, F9, H9, E12 }\end{array}$ \\
4 & D10, E10 & $\begin{array}{l}\text { 5'-monophosphate } \\
\text { pH 9.5+L-proline, pH 9.5+L-tyrosine, } \\
\text { pH 4.5+5-hydroxytryptophan }\end{array}$ \\
10 & F3, F7,D9 & Nickel chloride, cupric chloride \\
13 & A11-12, H1-4 & Nordihydroquaiaretic acid \\
15 & D11-12 & Rifamycin SV, L-glutamic acid g-hydroxamate \\
16 & E11-12; G9 & Niaproof, tannic acid, cefoperazone \\
17 & E4, F9-12, G11 & Myricetin \\
18 & G11,12 & Harmane, iodonitro tetrazolium violet \\
19 & A5-8, D6-8 & Lawsone, hexamminecobalt (III) chloride \\
19 & E9-12, H4 & Benserazide, crystal violet \\
20 & A9-12, E1-4 &
\end{tabular}

continue to grow but not via sulfate reduction, a possibility when alternate carbon source and yeast extract are present (Postgate, 1984). Therefore, as stated earlier, observed growth patterns should be confirmed by secondary methods such as cell counts or protein assays.

The use of opacity to visualize growth also presents some challenges for data interpretation. The observation that addition of medium in the absence of cells causes an immediate reaction in some wells is an artifact of the PM plates. Some wells components may also abiotically reduce sulfate to sulfide and cause formation of precipitate. It was found that several wells consistently have abiotic reactions that preclude the measurement of any opacity change due to cell growth and cannot be used to evaluate the $D$. vulgaris phenotype. Using the PMColorMap viewer (Fig. 8b), a list of these wells was identified and is given in Table 3.

Some wells have more minor abiotic background reactions which affect visualization of growth of $D$. vulgaris. For example, the PM 10 plate evaluates $\mathrm{pH}$ effects, and the first row contains reagents to control the $\mathrm{pH}$ in a range of 4.6-8.5 (this represents the actual measured $\mathrm{pH}$ range in LS4D media; PM 10 reported range given by Biolog is 3.5-10). The data (Fig. 6a) show poor or no growth below pH 6.9 and consistent growth from $\mathrm{pH}$ 6.9-pH 7.9. At $\mathrm{pH} 8.2$ and above, there are abiotic reactions with the medium raising the initial OL unit. Background abiotic reactions are about $80 \mathrm{OL}$ units for $\mathrm{pH} 7.9$ and $130 \mathrm{OL}$ units for $\mathrm{pH}$ 8.2. The background values may be due to precipitation or other reactions by well
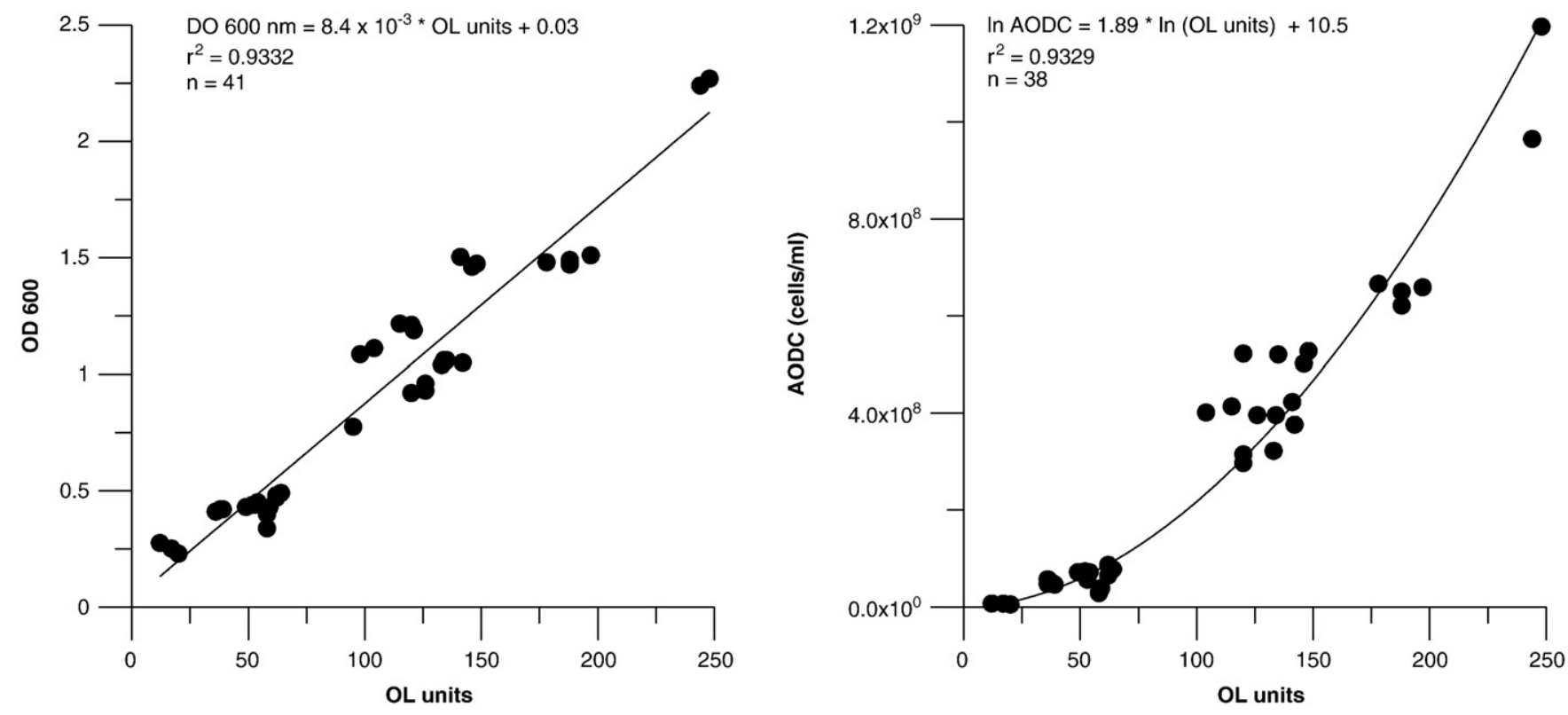

Fig. 5. Calibration of D. vulgaris with AODC (cell counts) and OD $600 \mathrm{~nm}$. OD $600 \mathrm{~nm}$ values over 1.0 absorbance units were diluted prior to measurement. 

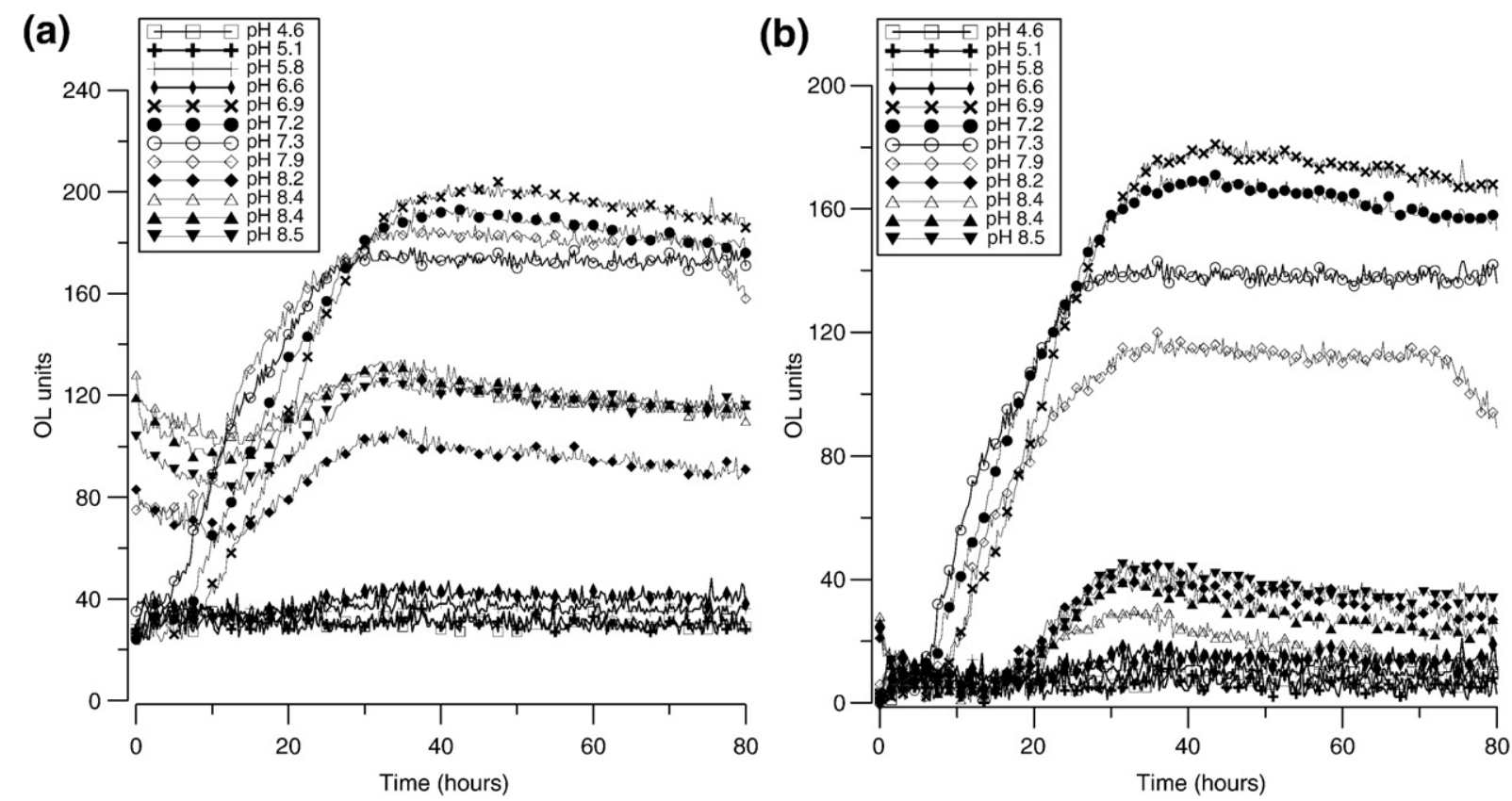

Fig. 6. PM microplate 10 row A (pH sensitivity). Plot (a) is raw data, plot (b) is the same data with the minimum value subtracted from each growth curve. Displayed pH is the measured value at time of inoculation.

components with LS4D, poor mixing, or changes in aggregation patterns of the cells. While these background values make absolute determination of the effect of $\mathrm{pH}$ on growth difficult, comparisons between conditions or strains using the same medium still would be possible. The growth curves also can be corrected by subtraction of the background value (Fig. 6b). For this assay of pH effects, comparing absolute minimum or maximum OL units is not informative in determining the effects of $\mathrm{pH}$. However, both the generation time, lag time and the difference between the maximum and the minimum OD might be used in evaluating effects of $\mathrm{pH}$ in a comparative study. An additional consideration is that depending on the buffer capacity and chemical composition of the growth media, the $\mathrm{pH}$ adjustment indicated for an OL well may not be accurate and should be measured independently.

Plates PM 1 and PM 2 are designed to evaluate carbon utilization patterns. The carbon source in the wells is $\sim 20 \mathrm{mM}$, which is too low to elicit robust growth of $D$. vulgaris. In this case, the addition of $10 \mathrm{mM}$ Fe-NTA to the medium increased the FeS precipitation and as a result, the opacity. However, while the additional Fe-NTA boosted the intensity for visualization, a growth curve was not obtained, and the result can be used only as an indication of carbon utilization capabilities, rather than as a kinetic assay. Using PM 1 and PM 2, D. vulgaris was shown to have growth on lactate and pyruvate and formic acid, as is reported in the literature (Heidelberg et al., 2004). These $C$ utilization results were further confirmed by measuring cell density and $D$. vulgaris purity was confirmed with PCR probes.

PM 4 is a split plate, the first five rows evaluate P sources and the remainder evaluates $S$ sources. It was found that the $S$ concentration in these wells were insufficient to support growth of $D$. vulgaris so the $S$ phenotype could not be determined.

While each plate and individual wells are labeled by basic description, Biolog ${ }^{\mathrm{TM}}$ has not yet released the detailed component description of each prepared well. Hence a well description such as 5\% $(\mathrm{wt} / \mathrm{vol}) \mathrm{NaCl}$ refers to the primary component in the well, but the well may contain other components that may affect cell growth. For example, growth of $D$. vulgaris on plate PM 9 row A is shown in Fig. 7. This plate assays growth from 1 to $10 \%(0.56-5.6 \mathrm{M}) \mathrm{NaCl}$ and measures the effect of increasing $\mathrm{NaCl}$ concentration on growth, and D. vulgaris demonstrates positive growth at the 1 and $2 \%$ levels. Previous results have shown the minimum inhibitory concentration of
$\mathrm{NaCl}$ to D. vulgaris in LS4D to be and addition of $0.44 \% \mathrm{NaCl}(0.250 \mathrm{M})$ to Na salts already present, namely sodium lactate and sodium sulfate (Mukhopadhyay et al., 2006). The increased resistance to $\mathrm{NaCl}$ shown in Fig. 7 is potentially due to the $0.2 \%$ yeast extract $(\mathrm{YE})$ present in the plates, added by Biolog as a fixing agent. YE is known to contain components such as glutamate, proline and glycine betaine (Dulaney et al., 1968) that may be used by D. vulgaris as an osmoprotectant (Mukhopadhyay et al., 2006). Limited growth of D. vulgaris was observed in a user prepared plate with $2 \% \mathrm{NaCl}$ with $0.2 \% \mathrm{YE}$ added, and was only observed up until $1 \% \mathrm{NaCl}(0.56 \mathrm{M})$ without $\mathrm{YE}$ (data not shown). This reemphasizes that the OL serves best as a tool to survey

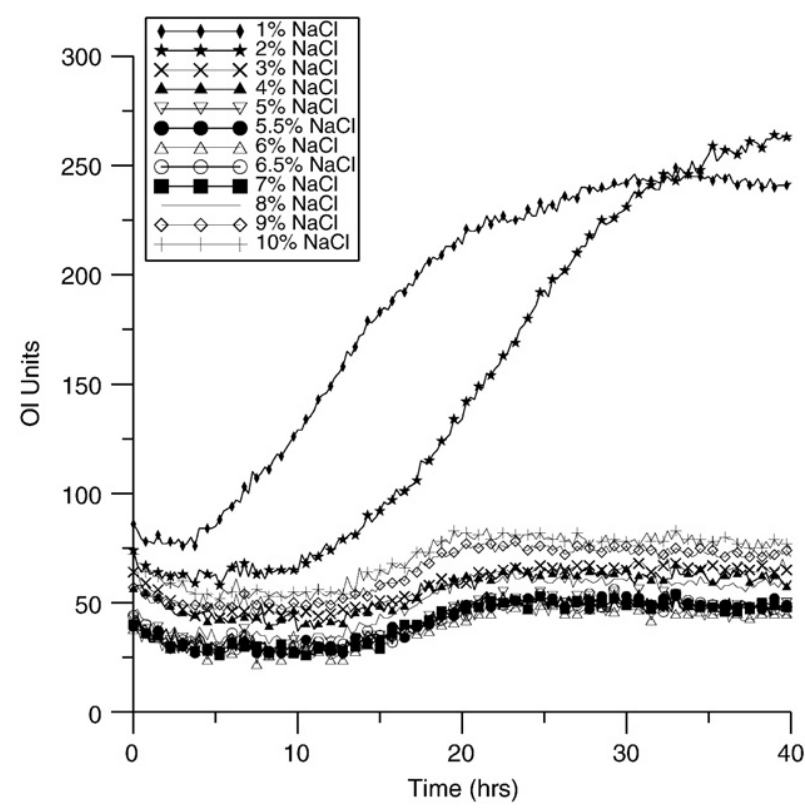

Fig. 7. PM 9 row $\mathrm{A}$, effects of increasing $\mathrm{NaCl}$ concentration on growth. Note that PM 9 plate contains $0.2 \%$ Yeast extract (YE) as a fixing agent. YE may affect the ability of an organism to cope with salt stress (For instance, YE typically contains components such as glutamate, proline and glycine betaine known to serve as osmoprotectants for D. vulgaris) 
(a)

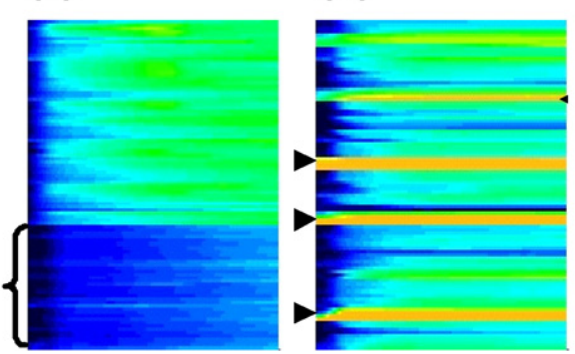

(c)

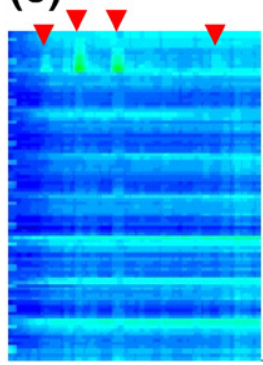

Fig. 8. False color images (see text) used to detect problem microplates: (a) several rows of wells, indicated by left brace, are under inoculated, (b) high turbidity indicated by black arrows and orange lines are due to chemical reactions between the growth medium and well treatment, (c) spikes in signals indicated by red arrows and vertical banding are due to instrument malfunction. The color legend for these plots is shown in Fig. 2.

phenotype, while the precise determination of inhibitory concentrations, antibiotic resistance patterns, etc., in a specific media require experiments in that defined medium either in user-prepared plates or flasks. In other words, results from the PM array, although inoculated with LS4D, actually reflect growth of LS4D plus PM media, which will be different than pure LS4D in most wells since the wells on many of the other plates also contain stabilizers or undefined buffers.

Further examples of growth visualization problems are shown in Fig. 8. Partial plate under-inoculation is clearly seen in Fig. 8a, with the lower third of the plate demonstrating no growth. In Fig. 8b yellow and orange bands indicate abiotic reactions between LS4D and PM well contents. Fig. $8 \mathrm{c}$ is a visualization of an $\mathrm{OL}$ instrument malfunction that caused periodic spikes in the data for this plate. These examples show that PMColorMap plots are valuable in rapid screening of plate validity, which may not be apparent from looking at individual growth curves.

\section{Conclusions}

A phenotype survey of $D$. vulgaris can be used as a basis for comparison of a variety of growth conditions, effects of stressors, or for the evaluation of knock out mutants. The PM array can provide a shotgun approach for screening, allowing the researcher to find potentially interesting growth changes that were not previously considered. Monitoring growth in the plates using FeS precipitate and cell accumulation can be correlated well with cell counts and OD 600 $\mathrm{nm}$ measurements traditionally used to monitor growth. The small well size and manufacturing process of PM plates can lead to observable differences between measurements for observed results. Evaporation, transfer of headspace gases between wells, presences of osmolytes in fixing agents (such as the presence of yeast extracts in PM 9), and $\mathrm{pH}$ changes will occur during growth. Results should be used with some reservations when evaluating kinetic data because abiotic or other chemical reactions in the wells can affect measured values for some wells. Despite the existence of unusual abiotic reactions among medium components and/or metabolic products, the growth information can still be useful as long as the abiotic features are recognized. Observed growth and interesting phenotypic changes should always be confirmed by cell counts, user prepared MT plates, or subsequent larger scale batch studies. Looking at a suite of growth parameters, both kinetic and absolute metrics, including generation time, the overall change in opacity as measured by OL units, and the lag time, will provide a clearer picture of the growth characteristics and overall phenotype. For increased confidence in observed phenotypes, biological triplicates and confirmation of observed growth in user prepared plates or in batch culture is recommended. Also important is monitoring of control wells to observe overinoculation and normalizing the inoculum of new or unknown strains for consistent growth. Despite these limitations the OL system is a valuable tool for broad screening of phenotypes for $D$. vulgaris and other such environmentally important sulfate/metal reducing bacteria.

Development of the PMViewer Web-based data viewers facilitated the sharing of data among project participants, assessment of the overall quality of phenotype surveys, and the identification of substrates that resulted in abiotic reactions. Using a color mapping technique to represent growth curves as thin color images, we were able to display large numbers of growth curves in a space-efficient way. We added to this the ability to filter views of the data and to zoom in on data from plates, rows on plates, or individual wells of interest. The PMViewer software tools have proven valuable for viewing the large amounts of data necessary for development of phenotype microarrays as a screening tool for $D$. vulgaris growth.

The above discussion highlights some observations for the PM survey for $D$. vulgaris across the various carbon requirements in addition to salt, osmotic and $\mathrm{pH}$ stress. This complete dataset for $D$. vulgaris is available in the supplementary data. The focus of this study is the optimization of the OL workflow for D. vulgaris, and this data set merits a more comprehensive analysis, which would constitute a separate study.

\section{Acknowledgements}

We would like to thank to Professor Judy Wall of University of Missouri for careful review and expert input into the manuscript. We would also like to thank Jeff Carlson, Barry Bochner, and Peter Gadinsky from Biolog for help in methods development. This work is part of the Virtual Institute for Microbial Stress and Survival (http:// vimss.lbl.gov) supported by the U.S. Department of Energy, Office of Science, Office of Biological and Environmental Research, Genomics: GTL Program through contract DE-AC02-05CH11231 between the Lawrence Berkeley National Laboratory and the US Department of Energy.

\section{Appendix A. Supplementary data}

Supplementary data associated with this article can be found, in the online version, at doi:10.1016/j.mimet.2008.10.003.

\section{References}

Bhupathiraju, V.K., Hernandez, M., Landfear, D., Alvarez-Cohen, L., 1999. Application of a tetrazolium dye as an indicator of viability in anaerobic bacteria. Journal of Microbiological Methods 37 (3), 231-243.

Bochner, B., 2003. New technologies to assess genotype-phenotype relationships. Nature Reviews/Genetics 4, 309-314.

Brewster, J.D., 2003. A simple micro-growth assay for enumerating bacteria. Journal of Microbiological Methods 53, 77-86.

Caumette, P., 1993. Ecology and physiology of phototrophic bacteria and sulfatereducing bacteria in marine salterns. Experientia 49 (6-7), 473-481.

Chang, I.S., Kim, B.H., 2007. Effect of sulfate reduction activity on biological treatment of hexavalent chromium $[\mathrm{Cr}(\mathrm{VI})]$ contaminated electroplating wastewater under sulfate-rich condition. Chemosphere 68 (2), 218-226.

Cottrell, M.T., Cary, S.C., 1999. Diversity of dissimilatory bisulfite reductase genes of bacteria associated with the deep-sea hydrothermal vent polychaete annelid Alvinella pompejana. Applied and Environmental Microbiology 65 (3), 1127-1132.

Demain, A.L., Newcomb, M., Wu, J.H., 2005. Cellulase, clostridia, and ethanol. Microbiology and Molecular Biology Reviews 69, 124-154.

Dulaney, E.L., Dulaney, D.D., Rickes, E.L., 1968. Factors in yeast extract which relieve growth inhibition of bacteria in defined medium of high osmolarity. Developments in Industrial Microbiology 9, 260-269.

Francisco, D., Mah, R.A., Rabin, A., 1973. Acridine orange epifluorescence technique for counting bacteria in natural waters. Transactions of the American Microscopical Society 92 (3), 416-421.

Gabrielson, J., Hart, M., Jarelov, A., Kuhn, I., Mckenzie, D., Mollby, R., 2002. Evaluation of redox indicators and the use of digital scanners and spectrophotometer for quantification of microbial growth in microplates. Journal of Microbiological Methods $50,63-73$.

Gellert, G., 2000. Sensitivity and significance of luminescent bacteria in chronic toxicity testing based on growth and bioluminescence. Exotoxicology and Environmental Safety 45, 87-91. 
Grostern, A., Edwards, E.A., 2006. Growth of Dehalobacter and Dehalococcoides spp. during degradation of chlorinated ethanes. Applied and Environmental Microbiology $72,428-436$.

Heidelberg, J.F., Seshadri, R., Haveman, S.A., Hemme, C.L., Paulsen, I.T., Kolonay, J.F., Eisen, J.A., Ward, N., Methe, B., Brinkac, L.M., Daugherty, S.C., Deboy, R.T., Dodson, R.J. Durkin, A.S., Madupu, R., Nelson, W.C., Sullivan, S.A., Fouts, D., Haft, D.H., Selengut, J., Peterson, J.D., Davidsen, T.M., Zafar, N., Zhou, L.W., Radune, D., Dimitrov, G., Hance, M., Tran, K., Khouri, H., Gill, J., Utterback, T.R., Feldblyum, T.V., Wall, J.D., Voordouw G., Fraser, C.M., 2004. The genome sequence of the anaerobic, sulfate-reducing bacterium Desulfovibrio vulgaris Hildenborough. Nature Biotechnology 22 (5) 554-559.

Jacobsen, J.S., Joyner, D.C., Borglin, S.E., Hazen, T.C., Arkin, A.P., Bethel, E.W., 2007 Visualization of growth curve data from phenotype microarray experiments. 11th International Conference on Information Visualization IV, Zürich, Switzerland. IEEE Computer Society Press.

Koutny, M., Zaoralkova, L., 2005. Miniaturized kinetic growth inhibition assay with denitrifying bacteria Paracoccus denitrificans. Chemosphere 30, 49-54.

Martinez, R.J., Beazley, M.J., Taillefert, M., Arakaki, A.K., Skolnick, J., Sobecky, P.A., 2007. Aerobic uranium (VI) bioprecipitation by metal-resistant bacteria isolated from radionuclide- and metal-contaminated subsurface soils. Environmental Microbiology 9 (12), 3122-3133.

Mukhopadhyay, A., He, Z.L., Alm, E.J., Arkin, A.P., Baidoo, E.E., Borglin, S.C., Chen, W.Q. Hazen, T.C., He, Q., Holman, H.Y., Huang, K., Huang, R., Joyner, D.C., Katz, N., Keller, M. Oeller, P., Redding A., Sun, J., Wall, J., Wei, J., Yang Z.M., Yen, H.C., Zhou, J.Z Keasling, J.D., 2006. Salt stress in Desulfovibrio vulgaris Hildenborough: an integrated genomics approach. Journal of Bacteriology 188 (11), 4068-4078.

Neculita, C.M., Zagury, G.J., Bussiere, B., 2007. Passive treatment of acid mine drainage in bioreactors using sulfate-reducing bacteria: critical review and research needs. Journal of Environmental Quality 36 (1), 1-16.
Noguera, D.R., Brusseau, G.A., Rittmann, B.E., Stahl, D.A., 1998. Unified model describing the role of hydrogen in the growth of Desulfovibrio vulgaris under different environmental conditions. Biotechnology and Bioengineering 59 (6), 732-746.

Postgate, J., 1984. The Sulphate-Reducing Bacteria, 2nd edition. Cambridge University Press, Cambridge, MA.

Postgate, J.R., Campbell, L.L., 1966. Classification of Desulfovibrio species nonsporulating sulfate-reducing bacteria. Bacteriological Reviews 30 (4), 732-737.

Sani, R.K., Peyton, B.A., Jandhyala, M., 2003. Toxicity of lead in aqueous medium to Desulfovibrio desulfuricanis G20. Environmental Toxicology and Chemistry 22 (2), 252-260.

Schmitz, R., Eisentrager, A., Dott, W., 1999a. Agonistic and antagonistic toxic effects observed with miniaturized growth and luminescence inhibition assays. Chemosphere 38 (1), 79-95.

Schmitz, R., Kretkowski, C., Eisentrager, A., Dott, W., 1999b. Ecotoxicological testing with new kinetic Photorhabdus luminescens growth and luminescence inhibition assays in microtitration scale. Chemosphere 38 (1), 67-78.

Telang, A.J., Voordouw, G., Ebert, S., Sifeldeen, N., Foght, J.M., Fedorak, P.M., Westlake, D.W.S. 1994. Characterization of the diversity of sulfate-reducing bacteria in soil and mining waste-water environments by nucleic-acid hybridization techniques. Canadian Journal of Microbiology 40 (11), 955-964.

Wind, T., Stubner, S., Conrad, R., 1999. Sulfate-reducing bacteria in rice field soil and on rice roots. Systematic and Applied Microbiology 22 (2), 269-279.

Yi, Z.J., Tan, K.X., Tan, A.L., Yu, Z.X., Wang, S.Q., 2007. Influence of environmental factors on reductive bioprecipitation of uranium by sulfate reducing bacteria. International Biodeterioration \& Biodegradation 60 (4), 258-266. 